\title{
ESTRUTURA POLÍTICO-ADMINISTRATIVA DOS GOVERNOS MUNICIPAIS DO PIAUÍ E INVESTIMENTO NO ESPORTE E NO LAZER
}

\author{
Recebido em: 24/12/2017 \\ Aceito em: 15/08/2018 \\ Edmilson Santos dos Santos \\ Universidade Federal do Vale do São Francisco \\ Petrolina - PE - Brasil \\ Fernando Augusto Starepravo \\ Universidade Estadual de Maringá (UEM) \\ Maringá - PR - Brasil
}

RESUMO: A participação dos governos municipais no investimento do esporte e do lazer é uma temática ainda pouco estudada e pouco se sabe sobre o assunto. Consequentemente, não temos informações se ter uma secretaria exclusiva de esporte aumentaria os investimentos. Nesse sentido, o presente estudo, de natureza descritiva buscou analisar se a estrutura político administrativa das prefeituras municipais do estado do Piauí interfere na capacidade de investimentos na Função Desporto e Lazer (FDL) per capita no ano de 2013. Concluiu-se que a estrutura político administrativa não interferiu na capacidade de gasto per capita na FDL.

PALAVRAS CHAVE: Políticas Públicas. Esportes. Atividades de Lazer. Federalismo. Descentralização.

\section{POLITICAL-ADMINISTRATIVE STRUCTURE OF MUNICIPAL GOVERNMENTS IN PIAUÍ AND INVESTMENT IN SPORT AND LEISURE}

ABSTRACT: The participation of municipal governments in investment in sport and leisure is still a less investigated topic and little is known regarding it. As a consequence, there are no information whether having an exclusive sport office would increase investments. For that matter, the present descriptive study aimed to analyze if the political-administrative structure of municipal governments in the state of Piauí had any interference in the per capita investment capacity in the Sports and Leisure Function (SLF) in 2013. It was concluded that the political-administrative structure has not interfered in the expense per capita capacity in SLF.

KEYWORDS: Public Policy. Sports. Leisure Activities. Federalism. Decentralization. 


\section{Introdução}

Nas últimas décadas houve aumento importante das análises nacionais dos gastos que tem permitido acurar nosso olhar sobre os gastos na esfera do governo federal nas políticas públicas de esporte e de lazer (CASTRO, 2016; ATAHYDE, 2016; ATHAYDE; MASCARENHAS; SALVADOR, 2015; FIGUREOA et al, 2014; ALMEIDA; MARCHI Jr., 2010; VERONEZ, 2007). Considerando o volume de municípios no Brasil (5.570), essa realidade carece de atenção maior por parte da policy community da área de políticas públicas de esporte e de lazer. Talvez, parte desta pouca atenção esteja associada à baixa expectativa de que os municípios irão aportar recursos em uma área em que não há constrangimentos da federação quanto a sua efetiva participação no financiamento de políticas públicas de esporte e de lazer.

No artigo que trata das competências do poder público municipal (Art. 30 da Constituição Federal de 1988), a área do esporte não foi apontada como sendo atribuição dos municípios. Nesse caso, os incentivos da federação são em direção à inação. No entanto, alguns estudos, sobretudo na análise da participação dos governos locais na implementação de políticas públicas de esporte e de lazer, têm demonstrado que políticas têm sido implementadas pelo poder público municipal. Seja no desenvolvimento de sua própria agenda (descentralização bottom-up), seja implementando a agenda política do governo federal (descentralização top-down) (SABATIER, 1986).

Esses trabalhos demonstram intensa atividade política em torno da agenda esportiva nos municípios brasileiros (SANTOS; STAREPRAVO; HIRATA, 2018; BETTIN; PEIL; MELO, 2018; GRASSO; ISAYAMA, 2017; MERTINS; MYSKIW; SANFELICE, 2016; SANTOS, 2016; NASCIMENTO; LAZZAROTTI FILHO; 
INÁCIO, 2015; VENTURIM; BORGES; SILVA, 2013; SILVA; COUTO; SANTOS, 2014; LUZ, 2011; BANKOFF; ZAMAI, 2011; BRUST; BAGGIO; SALDANHA FILHO, 2006).

No entanto, há um déficit de estudos que colocam os municípios como lócus investigativo para analisar os investimentos realizados na Função Desporto e Lazer (FDL). A FDL é a unidade de gasto criada pelo Estado brasileiro para avaliar o financiamento do esporte (BRASIL, 1999). Ao analisarem o gasto na FDL pelos municípios da Bahia; Santos; Canan e Starepravo (2018) identificaram que, apesar dos constrangimentos em direção à inação, os municípios apresentaram elevada adesão a esse nível de gasto.

Essa realidade coloca como desafio não somente aferir o grau de participação dos municípios no gasto na FDL, mas também compreender que variáveis intervenientes afetam seu resultado. Nesse sentido, o presente trabalho desenvolvido pelo Centro de Desenvolvimento de Pesquisas em Políticas de Esporte e Lazer do Piauí buscou realizar análise comparativa dos investimentos na FDL das prefeituras do estado do Piauí. A variável escolhida para avaliar o desempenho foi a existência de estrutura administrativa no nível de primeiro escalão. A pergunta da pesquisa que orientou o estudo foi: prefeituras que possuem secretarias exclusivas de esporte e de lazer gastam mais per capita na FDL que as outras formas de organização político-administrativo?

Para consecução dessa análise, organizamos o trabalho em quatro etapas. $\mathrm{Na}$ primeira, discutimos o impacto do federalismo brasileiro na capacidade de gastos dos municípios. Em seguida, apresentamos a metodologia e a discussão dos resultados, e finalmente, as considerações finais. 


\section{Federalismo e Políticas de Esporte e Lazer}

A literatura neoinstitucionalista coloca a estrutura político-administrativa da gestão dos governos como variável importante para se compreender a formulação e implementação de políticas públicas em nosso federalismo. O neoinstitucionalismo, corrente das Ciências Sociais que tem ressaltado enfaticamente a importância das instituições para o entendimento dos processos sociais, não se configura como uma corrente teórica unitária, mas aproxima um grande número de pesquisadores que entendem as instituições como centrais nas análises relativas aos processos políticos e sociais. Segundo seus seguidores, é uma teoria de médio alcance, baseada em afirmações a serem testadas e alteradas a partir da realização de estudos específicos (MARQUES, 1996).

As diferenças mais significativas do neoinstitucionalismo em relação a outras abordagens da Ciência Política estão relacionadas ao nexo explicativo dos processos e fenômenos políticos. Identificam as instituições enquanto variáveis independentes, com capacidade explicativa sobre os resultados políticos concretos e determinação sobre alguns traços do comportamento sócio-político dos indivíduos e grupos (TOMIO, 2002).

Como para o neoinstitucionalismo as instituições são centrais, cabe discorrer sobre seu significado. Marques (1996) faz uma analogia ao esporte para definir o que seriam as instituições e os atores sociais, onde os atores sociais poderiam ser comparados aos jogadores de uma partida esportiva e as instituições seriam a delimitação do campo e as regras do jogo. Para Marques (1996), instituições incluem regras formais, procedimentos consentidos, práticas operacionais padronizadas que estruturam as relações entre indivíduos em várias unidades da política e da economia. 
Este conceito não é consensual, entendendo outros autores, que há um grau maior de formalidade nas instituições, que por repousarem sobre aspectos legais e estrutura definida, se distinguem das normas, cujos incentivos são mais cognitivos e sociais (MARQUES, 1996).

Como sabemos o Estado brasileiro não delegou obrigações para formulação e implementação de políticas públicas de esporte e de lazer a nenhum ente federado. Apesar de apontar o direito, não regulamentou sua consecução ${ }^{1}$. Portanto, a chave para se compreender as políticas públicas está associada ao que o nosso federalismo pode ofertar em termos de incentivos à descentralização (MINHOTO, 2014).

Essa realidade não é vivida apenas nas políticas de esporte e de lazer. Outras políticas sociais, não reguladas por norma (política de Estado), também são dependentes de decisões discricionárias do governante. Em políticas que são de competências comuns (todos os entes federados podendo agir) o que afeta a capacidade de decisão são os estímulos colocados pelo governo para que eles concorram entre si (Art. $24 \mathrm{CF} / 88$ ) ou pelos incentivos dos entes superiores à cooperação (ALMEIDA, 2005).

Um governo pode ofertar uma política já implementada por outro ente federado a fim de conquistar a simpatia do eleitorado por desenvolver uma proposta mais eficiente. Ele pode também diminuir os custos de transação ${ }^{2}$ compartilhando a ação com outro ente federado. Assim, todos têm sua parcela de responsabilidade na política e também podem partilhar os ganhos políticos dessa ação.

\footnotetext{
${ }^{1}$ A Constituição Federal de 1988 não indicou responsabilidades na implementação de políticas públicas de esporte e lazer.

${ }^{2} \mathrm{O}$ custo da transação se refere a quanto um ente teria que gastar para implementar só uma dada política. Desde a formulação técnica até a implementação. Não tendo um operador direto na ponta, muitas vezes o menor custo é ofertando a política para outro ente implementar. Assim, compartilham-se os custos, não só econômicos, de toda a efetivação (transação) da proposta.
} 
Não havendo possibilidade de impor agenda política de um ente superior para um inferior, aumentam as dificuldades para se cumprir um dos objetivos centrais de uma federação, expresso no Inciso 3 do Art. 3 da CF/88. Muito embora seja preciso registrar que a existência por si só de 3 entes federados (única dentre as 28 federações), tal arranjo, dificulta muito a implementação de políticas públicas que visam diminuir desigualdades (COSTA, 2010; ARRETCHE; MARQUES, 2007; MARQUES; ARRETCHE, 2003).

Por outro lado, do ponto de vista fiscal somos a federação mais descentralizada do mundo. Garantimos aportes de recursos importantes aos municípios sem a necessidade de submissão aos interesses de outros entes superiores (estados e União). Primeiro, garantindo aos municípios o direito de legislar sobre três impostos: Imposto Predial e Territorial Urbano (IPTU), Imposto sobre Serviços de Qualquer Natureza (ISQN) e Imposto sobre Transferências de Bens Intervivos (ITBI). Segundo, garantindo percentual do Fundo de Participação dos Municípios (FPM). Terceiro, garantindo a cota parte do Imposto de Circulação de Mercadoria e Serviços (ICMS). Portanto, do ponto de vista fiscal, há recursos para a formulação e implementação de políticas públicas no âmbito local de forma autônoma (CASTRO et al, 2009), apesar de distribuída de forma desigual na federação.

Como não há equalização das condições financeiras dos municípios, a autonomia de gasto tende a promover desigualdades na oferta de serviços (ARRETCHE, 2010). Cada município investe com base naquilo que arrecada com o regime fiscal próprio ou com as transferências constitucionais (FPM e ICMS). Os municípios foram os grandes beneficiários da descentralização tributária pósconstituição e aumentaram bastante sua capacidade para produzir política (CARNEIRO; 
ALMEIDA, 2008; SANTOS, 2011). Para Arretche (2010), há excessiva autonomia dos governos locais, o que acaba por diminuir os recursos necessários para garantir maior equidade nas políticas sociais ${ }^{3}$.

Como destaca Souza (2005), as diferenças econômicas produzem diferenças na capacidade decisória. Sendo assim, a capacidade de promover serviços sociais, como as políticas públicas de esporte e de lazer, é desigual (SOUZA, 2001). Nesse sentido, a oferta desigual ou diferente de políticas públicas é da natureza do federalismo brasileiro. A maior equalização das políticas só pode ser alcançada com maior participação dos entes superiores na implementação das políticas públicas.

\section{Materiais e Métodos}

O presente estudo de natureza descritiva buscou analisar se a estrutura políticoadministrativa de primeiro escalão das prefeituras municipais do estado do Piauí (n = 224) interfere na capacidade de investimentos na FDL no ano de 2013. Para tanto, estabelecemos nossas hipóteses de trabalho nos seguintes termos:

H1. Prefeituras com secretarias de esporte e de lazer exclusiva investem mais per capita na FDL que prefeituras que não possuem secretarias.

H2. Prefeituras com secretarias de esporte e de lazer exclusiva investem mais per capita na FDL que prefeituras que compartilham a administração com outras áreas.

As informações referentes à FDL foram capturadas junto ao site da Secretaria do Tesouro Nacional (https://siconfi.tesouro.gov.br/siconfi/pages/publi) nos dados referentes às contas anuais no Sistema de Informações Contábeis e Fiscais do Setor Público Brasileiro - Siconfi, entre os dias 10 e 11 de junho de 2016 (STN, 2016). Os

\footnotetext{
${ }^{3}$ Para uma análise crítica do regime fiscal pós CF/88, ver Santos e Gentil (2009).
} 
dados compuseram uma planilha contendo o nome dos municípios do estado de Piauí, a estrutura organizativa dos municípios para implementação de políticas públicas de esporte e de lazer e da população das cidades, conforme o censo de 2010 do IBGE.

A estrutura organizativa para implementação de políticas públicas de esporte e de lazer contemplaram três realidades: a) secretarias exclusivas de esporte (podendo compor com o lazer) (Ex); b) secretaria de esporte junto com outras secretarias (Ou); c) sem estrutura administrativa de primeiro escalão (Sem). As informações referentes à estrutura organizativa foram capturadas diretamente no site das prefeituras no período de 4 a 12 de outubro de 2016.

A classe populacional foi organizada de forma a comtemplar 4 realidades: a) CP1, municípios até 5 mil habitantes; b) CP2, entre 5 mil e 10.000; c) CP3, entre 10.001 habitantes até 20 mil habitantes; d) CP4, entre 20.001 habitantes até 50 mil habitantes; CP5, acima de 50 mil habitantes.

\section{Resultados e Discussão}

A literatura sobre gastos dos governos no federalismo suporta que nas despesas discricionárias, aquela não regulada por normas exista diferenças e por vezes desigualdade na oferta de serviços à população (ARRETCHE, 2010). Como pode ser observado na tabela1, os valores per capita mais baixos de investimento na FDL não variam com o tamanho da cidade e os maiores valores assumem vetor decrescente. $\mathrm{Ou}$ seja, o aumento no tamanho da cidade impacta de forma a diminuir a quantidade de recurso disponível por habitante. De outra forma, municípios pequenos dispõem de maior quantidade de recurso por habitante para investimentos em políticas públicas de esporte e de lazer. 
Tabela 1: Níveis de investimento na FDL per capita por classe populacional do estado do Piauí.

\begin{tabular}{|c|c|c|c|c|c|c|c|}
\hline & \multirow[t]{2}{*}{$\mathrm{N}^{\mathrm{o}}$ Mun. } & \multicolumn{6}{|c|}{ Investimento na Função Desporto e Lazer } \\
\hline & & $\mathrm{N}^{\mathrm{o}} \mathrm{FDL}$ & Menor & Maior & Média & $\begin{array}{c}<\mathrm{R} \$ \\
12,00\end{array}$ & $\%$ \\
\hline CP1 & 83 & 72 & 0,01 & 80,24 & 15,30 & 56 & 67,47 \\
\hline CP2 & 81 & 67 & 0,07 & 77,77 & 10,45 & 61 & 75,31 \\
\hline CP3 & 35 & 33 & 0,06 & 46,34 & 9,44 & 24 & 68,57 \\
\hline $\mathrm{CP} 4$ & 20 & 17 & 0,28 & 24,02 & 8,17 & 16 & 80,00 \\
\hline CP5 & 5 & 5 & 0,66 & 23,22 & 7,25 & 4 & 80,00 \\
\hline
\end{tabular}

Fonte: Dados da pesquisa.

Chama atenção o percentual de cidades que investem menos de $\mathrm{R}$ 1,00 mês (R\$ 12,00 ano). No Piauí, as cidades até 5 mil habitantes conseguem investir mais que as cidades maiores. O cenário apresenta-se bastante diverso. Sem uma métrica para saber se o investido é pouco ou suficiente frente às necessidades da população local, não é possível estabelecer paralelos fixos entre a desigualdade e a diferença, nesse caso.

O volume de recursos disponibilizados para as políticas públicas de esporte e de lazer por parte dos municípios do Piauí foi de $\mathrm{R} \$$ 22.297.221,46. O investimento, apenas no ano de 2013 , é $24 \%$ do que foi investido com as políticas de esporte e de lazer no estado do Piauí pelo Ministério do Esporte de 2004 a 2011 (CASTRO, 2016) ${ }^{4}$. Ou seja, em um ano (2013) os municípios do Piauí gastaram o equivalente a 1/4 dos investimentos em 8 anos do Ministério do Esporte no estado. Os investimentos, por classe populacional, foram: $\mathrm{CP} 1: \mathrm{R} \$ 3.886 .758,42 ; \mathrm{CP} 2: \mathrm{R} \$ 5.158 .268,70 ; \mathrm{CP} 3: \mathrm{R} \$$ 4.652.192,45; CP4: R\$ 4.557.214,34; CP5: R\$ 4.042.787,55.

A questão central do estudo foi verificar o impacto da forma das estruturas de governança do esporte e do lazer no âmbito municipal nos investimentos na FDL. Como indica a Tabela 2, nas cidades até 5 mil habitantes não houve grande variação entre as administrações que possuem uma secretaria exclusiva (Ex) e as que não possuem

\footnotetext{
${ }^{4}$ Como não foi possível discriminar as descentralizações do Governo Federal por município e por ente federado (prefeituras ou governo estadual), consideramos, para efeito deste trabalho, os recursos descentralizados como compondo a análise do orçamento municipal.
} 
secretaria (Sem). Nesse cenário, a maior média de investimento se dá entre as administrações cuja pasta esportiva é compartilhada com outras áreas $(\mathrm{Ou})$ e é a que possui o menor percentual de cidades com menos de R\$ 1,00/mês (R\$ 12,00/ano) de investimentos nessa área $(55,56 \%)$.

Tabela 2: Níveis de investimento na FDL per capita por estrutura administrativa e CP1 do estado do Piauí.

\begin{tabular}{l|c|cccccc}
\hline \multirow{2}{*}{} & \multirow{2}{*}{ N $^{\text {o }}$ Mun. } & \multicolumn{5}{|c}{ Investimento na Função Desporto e Lazer } \\
\cline { 3 - 7 } & & $\mathrm{N}^{\text {o }}$ FDL & Menor & Maior & Média & $<\mathrm{R} \$$ & $\%$ \\
\hline Ex & 30 & 27 & 0,20 & 76,59 & 11,11 & 18 & 60 \\
Ou & 9 & 9 & 0,76 & 58,17 & 17,30 & 5 & 55,56 \\
Sem & 44 & 39 & 0,10 & 80,24 & 10,48 & 31 & 70,45 \\
\hline
\end{tabular}

Fonte: Dados da pesquisa.

Houve variação importante na quantidade total de recursos disponibilizados. A quantidade total de investimento parece sofrer, nesse caso, impacto do número de municípios: “Ou”, R\$ 612.853,19; “Ex”, R\$ 1.545.188,10; “Sem”, R\$ 1.728.717,13. A maior média de investimento se deu nas administrações que compartilham as políticas de esporte e de lazer com outras áreas $(\mathrm{R} \$ 17,30)$.

Tabela 3: Níveis de investimento na FDL per capita por estrutura administrativa e CP2 do estado do Piauí.

\begin{tabular}{|c|c|c|c|c|c|c|c|}
\hline & \multirow[t]{2}{*}{$\mathrm{N}^{\mathrm{o}}$ Mun. } & \multicolumn{6}{|c|}{ Investimento na Função Desporto e Lazer } \\
\hline & & $\mathrm{N}^{\mathrm{o}} \mathrm{FDL}$ & Menor & Maior & Média & $\begin{array}{c}<\mathrm{R} \$ \\
12,00\end{array}$ & $\%$ \\
\hline Ex & 28 & 24 & 0,07 & 77,77 & 8,88 & 21 & 75 \\
\hline $\mathrm{Ou}$ & 19 & 17 & 0,36 & 43,41 & 16,54 & 14 & 73,68 \\
\hline Sem & 34 & 26 & 0,21 & 47,76 & 7,78 & 25 & 73,53 \\
\hline
\end{tabular}

Fonte: Dados da pesquisa.

Assim como aconteceu no nível CP1, a maior média de investimento se dá entre as administrações “Ou” (R\$ 16,54). Há percentual muito próximo de cidades que investiram menos de $\mathrm{R} \$ 1,00 /$ mês por habitante $(73,53 \%, 73,68 \%, 75 \%)$, indicando não sofrer impacto da estrutura político-administrativa. O total de investimento por nível de organização político-administrativo ficou: "Ex" $\mathrm{R} \$ 2.016 .714,93$; “Sem” R\$ 1.927.199,36; “Ou” R\$ 1.214.354,41. As administrações com secretaria exclusiva, 
mesmo tendo menor " $n$ ", quando comparado com "Sem", tiveram maior investimento na FDL.

Tabela 4: Níveis de investimento na FDL per capita por estrutura administrativa e CP3 do estado do Piauí.

\begin{tabular}{|c|c|c|c|c|c|c|c|}
\hline & \multirow[t]{2}{*}{$\mathrm{N}^{\mathrm{o}}$ Mun. } & \multicolumn{6}{|c|}{ Investimento na Função Desporto e Lazer } \\
\hline & & $\mathrm{N}^{\mathrm{o}} \mathrm{FDL}$ & Menor & Maior & Média & $\begin{array}{c}<\mathrm{RS} \\
12,00\end{array}$ & $\%$ \\
\hline Ex & 18 & 17 & 0,29 & 32,47 & 10,45 & 11 & 61,11 \\
\hline $\mathrm{Ou}$ & 12 & 11 & 0,06 & 46,34 & 8,67 & 8 & 66,67 \\
\hline Sem & 5 & 5 & 1,30 & 11,76 & 6,40 & 5 & 100 \\
\hline
\end{tabular}

Fonte: Dados da pesquisa.

No terceiro nível (Tabela 4), pela primeira vez as secretarias exclusivas tiveram maior média de recursos investidos na FDL (R\$ 10,45) e menor percentual de municípios que gastam menos de R\$12,00 ano per capita. Por outro lado, foram as administrações "Sem" que romperam a barreira de investimento mínimo acima de R\$ 1,00, mas foi a única que em todas as cidades não alcançaram o valor de $\mathrm{R} \$ 12,00$ per capita. O maior investimento nominal ficou com as "Ex" R\$2.654.237,27 seguida das “Ou”: R\$ 1.651.234,58 e "Sem”: R\$ 346.720,60.

Tabela 5: Níveis de investimento na FDL per capita por estrutura administrativa e CP4 do estado do Piauí.

\begin{tabular}{l|c|c|c|c|c|c|c}
\hline \multirow{2}{*}{} & \multirow{2}{*}{$\mathrm{N}^{\text {o }}$ Mun. } & \multicolumn{5}{|c}{ Investimento na Função Desporto e Lazer } \\
\cline { 3 - 8 } & & $\mathrm{N}^{\text {o FDL }}$ & Menor & Maior & Média & $<\mathrm{R} \$$ & $\%$ \\
& & & & & & 12,00 & \\
\hline Ex & 7 & 5 & 2,93 & 21,40 & 9,52 & 6 & 85,71 \\
Ou & 10 & 9 & 0,28 & 24,20 & 10,88 & 7 & 70 \\
Sem & 3 & 3 & 3,61 & 7,74 & 5,70 & 3 & 100 \\
\hline
\end{tabular}

Fonte: Dados da pesquisa.

No nível 4 (CP4), Tabela 5, há uma variação importante, principalmente nos valores menores e maiores de investimento. Os valores menores, para o "Ex" e "Sem", rompeu a barreira do $\mathrm{R} \$ 1,00$. O menor nível de investimento per capita foi o maior alcançado nas administrações "Sem" (R \$ 5,70) e todas as prefeituras gastaram menos de 
R\$ 1,00 mês/ano por habitante. O melhor desempenho nesse quesito foi a "Ou", com $70 \%$ dos seus municípios investindo menos de $\mathrm{R} \$ 12,00$ ano per capita, além de ser a que mais investiu. Os investimentos na FDL por estrutura político-administrativa foram: “Ex” R\$ 1.371.142,69; “Ou” R\$ 2.604.117,01; “Sem” R\$ 581.354,64.

Tabela 6: Níveis de investimento na FDL per capita por estrutura administrativa e CP5 do estado do Piauí.

\begin{tabular}{l|c|c|c|c|c|c|c}
\hline \multirow{2}{*}{} & \multirow{2}{*}{$\mathrm{N}^{\text {o }}$ Mun. } & \multicolumn{6}{|c}{ Investimento na Função Desporto e Lazer } \\
\cline { 3 - 8 } & & $\mathrm{N}^{\mathbf{0}}$ FDL & Menor & Maior & Média & $<\mathrm{R} \$$ & $\%$ \\
& & & & & & 12,00 & \\
\hline Ex & 3 & 3 & 0,66 & 5,22 & 11,48 & 3 & 100 \\
Ou & 2 & 2 & 5,14 & 23,22 & 15,35 & 1 & 50 \\
Sem & - & - & - & - & - & - & - \\
\hline
\end{tabular}

Fonte: Dados da pesquisa.

No último nível (CP5), as estruturas "Ex" tiveram resultados inferiores ao "Ou" em todos os cenários (TABELA 6). Nesse caso, parece que ter estrutura administrativa não logrou êxito quanto aos investimentos na FDL, principalmente no que diz respeito aos municípios que investiram menos de $\mathrm{R} \$ 12,00$ ano per capita. E apesar de número maior de cidades com "Ex", os valores totais foram inferiores ao "Ou". "Ex" com R\$ 2.020.558,96 e “Ou” com R\$ 2.022.228,59, respectivamente.

A diversidade de resultados é própria do nosso regime federalista (ARRETCHE, 2010; SANTOS, 2011; SOUZA, 2001). Porém, é possível observar, no que diz respeito às hipóteses levantadas, que:

H1. Foi possível confirmar que no estado do Piauí as prefeituras com secretarias de esporte e de lazer exclusiva "Ex" investiram no ano de 2013 mais per capita na FDL que prefeituras que não possuíam secretarias "Sem". Realidade de todos os cenários (CP1, CP2, CP3 e CP4). 
H2. Não foi possível confirmar que no estado do Piauí as prefeituras com secretarias de esporte e de lazer exclusiva "Ex" investiram mais per capita na FDL que prefeituras que compartilham a administração com outras áreas "Ou”. Essa realidade só se fez presente na CP3; nas outras, prevaleceu os investimentos realizados por "Ou".

Nesse sentido, os resultados não permitem afirmar que ter uma secretaria exclusiva de esporte e de lazer eleva os investimentos per capita médio na FDL. Esses resultados comprometem a tese de que a existência de um ator político estratégico, secretário de esporte, se configura como um aspecto importante para elevar o valor médio per capita investido na FDL. Outras variáveis parecem atuar no sentido de produzir efeito sobre o gasto na FDL.

\section{Considerações Finais}

Em tempos de corte de gastos no setor público às políticas sociais, com aglutinação ou supressão de estruturas de primeiro escalão para formular e implementar políticas públicas de esporte e de lazer, os resultados aqui encontrados são desconcertantes. A estrutura político-administrativa não interferiu nos investimentos na FDL no ano de 2013. Tal descoberta contrapõe a agenda apresentada pela II Conferência Nacional de Esporte, que deliberou pela "Criação de pastas específicas de Esporte e Lazer nas esferas estaduais e municipais (Secretarias, Fundações, Autarquias), com autonomia administrativa e orçamentária, conselhos específicos e planos de desenvolvimento, para implementação e continuidade de políticas de esporte e lazer em todas as dimensões visando a inclusão social, e definindo prazo máximo para essa criação" (BRASIL, 2006), mas os resultados são perfeitamente compatível com o que 
aponta a literatura sobre descentralização de políticas sociais no federalismo brasileiro (ARRETCHE, 2010).

Sem um parâmetro para julgar os gastos a partir das preferências dos cidadãos, não é possível afirmar de forma peremptória que possuir estrutura administrativa de primeiro escalão leva, necessariamente, à elevação dos investimentos na FDL. Talvez a diferença esteja na qualidade do gasto público. As preferências podem estar associadas a uma das subfunções da FDL: desporto comunitário, desporto rendimento e lazer; ou na forma como esses investimentos são realizados.

Portanto, o federalismo suporta diferenças no financiamento quando produzidas por entes subnacionais. Elas podem estar ancoradas em variáveis que estão longe do alcance dos gestores locais como o perfil urbano do município, que impacta na arrecadação do IPTU (GOMES; DOWELL; CRISTINA, 2000), ou as preferências dos cidadãos em períodos de eleição que podem pressionar o governo a agir sobre outras agendas. Fica evidente na pesquisa que não temos também um padrão de investimento na FDL no estado do Piauí.

Os dados reforçam a necessidade de que mais que a "municipalização" das políticas públicas de esporte e de lazer (pois os gastos nos dizem que já está municipalizada) é necessário que as policy communities se debrucem sobre o gasto público municipal. Ou seja, que haja a municipalização da agenda de pesquisa em políticas públicas de esporte e de lazer para que possamos compreender melhor o financiamento das políticas de esporte e de lazer no Brasil. 


\section{REFERÊNCIAS}

ALMEIDA, B.S.; MARCHI JÚNIOR, W. O financiamento dos programas federais de esporte e lazer no Brasil (2004 a 2008). Movimento, Porto Alegre, v. 16, n. 4, p. 73-92, 2010.

ALMEIDA, M. H. T. Recentralizando a federação? Revista Sociologia Política. Curitiba, 24, p. 29-40. Jun, 2005.

ARRETCHE, M. Federalismo e igualdade territorial: uma contradição em termos? Dados, Rio de Janeiro, v. 53, n. 3, p. 587-620, 2010.

.; MARQUES, E. Condicionantes locais da descentralização das políticas de saúde. In: HOCHMAN, G.; ARRETCHE, M.; MARQUES, E. (Org.) Políticas públicas no Brasil. Rio de Janeiro: Ed. FIOCRUZ, 2007. p. 173-204.

ATHAYDE, P.F.A. A disputa pelo fundo público no âmbito do financiamento esportivo brasileiro. Revista Brasileira de Ciências do Esporte, Brasília, v. 36, 2016.

.; MASCARENHAS, F.; SALVADOR, E. Primeiras aproximações de uma análise do financiamento da política nacional de esporte e lazer no Governo Lula. Revista Brasileira de Ciências do Esporte, Brasília, v. 37, n. 1, p. 2-10, 2015.

BANKOFF, A.D.P.; ZAMAI, C.A. Estudos sobre políticas públicas de esporte e lazer de prefeituras municipais do Estado de São Paulo. Conexões, Campinas, v. 9, n. 2, p. 70-79, 2011.

BETTIN, E.B.; PEIL, L.M.N.; MELO, M.P. Políticas públicas municipais de esporte, lazer e espaços públicos em Pelotas-RS na gestão 2009-2012. Pensar a Prática, Goiânia, v. 21, n. 1. 96-106, 2018.

BRASIL. Constituição da República Federativa do Brasil (1988). Diário Oficial [da] República Federativa do Brasil, Brasília, DF, 05 out. 1988. Disponível em: $<$ https://www.planalto.gov.br/ccivil_03/Constituicao/Constituicao.htm>. Acesso em: 15 jan. 2017.

. Ministério do Planejamento, Orçamento e Gestão. Portaria n. ${ }^{\mathbf{0}}$ 42, de 14 de abril de 1999. Diário Oficial [da] República Federativa do Brasil, Brasília, DF, 14 abr. 1999. Disponível em: ftp://ftp.fnde.gov.br/web/siope/leis/P42_MPOG_14-041999.pdf . Acesso em: 10 mar. 2016.

BRASIL. Resoluções da II Conferência Nacional do Esporte (2006). Brasília. Disponível em: https://portal.esporte.gov.br/conferencianacional/propostas_aprovadas.jsp. Acesso em: 30 jan. 2007

BRUST, C.; BAGGIO, I.C; SALDANHA FILHO, M.F. Repensar a gestão das políticas públicas de esporte e lazer: O caso de Santa Maria/RS. Motrivivência, Florianópolis, a. XVIII, n. 27, p. 179-192, 2006. 
CARNEIRO, L. P.; ALMEIDA, M. H. T. Definindo a arena política local: sistemas partidários municipais na federação brasileira. Dados, Rio de Janeiro, v. 51, n. 2, p. 403 a 432, 2008.

CASTRO, J. A. et al. A CF/88 e as políticas sociais brasileiras. In: CARDOSO Jr., J. C. (Org.). A Constituição brasileira de 1988 revisitada: recuperação histórica e desafios atuais das políticas públicas nas áreas econômica e social. Brasília: Ipea, 2009, p. 55121.

CASTRO, S. B. E. Políticas públicas para o esporte e lazer e o ciclo orçamentário brasileiro (2004-2011): prioridades e distribuição de recursos durante os processos de elaboração e execução orçamentária. Universidade Federal do Paraná, Programa de PósGraduação em Educação Física, 2016. p. 382.

COSTA, V. M. F. C. Federalismo e relações intergovernamentais: implicações para a reforma da educação no Brasil. Educação e Sociedade, Campinas, v. 13, n. 112, p. 729-748, jul./set. 2010.

FIGUERÔA, K.M. et al. Planejamento, ações e financiamento para o esporte em tempos de megaeventos. Motrivivência, Florianópolis, v. 26, n. 42, p. 55-71, 2014.

GOMES, G.M.; DOWELL, M.; CRISTINA, M. Descentralização política, federalismo fiscal e criação de municípios: o que é mau para o econômico nem sempre é bom para o social. Texto para Discussão, Brasília, n. 706, 2000.

GRASSO, R. P.; ISAYAMA, H. F. Financiamento e políticas públicas de esporte e lazer: uma análise da gestão no município de Santarém/PA (2005-2012). Revista Brasileira de Ciência e Movimento, Brasília, v. 25, n. 1, p. 151-167, 2017.

LUZ, A. P. R. G. Análise das políticas públicas de esporte e lazer no município de João Pessoa-PB. 2011. João Pessoa: Universidade Estadual da Paraíba, 2011. 209 f. Gestão Pública, Universidade Estadual da Paraíba, João Pessoa, 2011.

MARQUES, E. Notas críticas a literatura sobre Estado, políticas estatais e atores políticos. BIB: Boletim Bibliográfico de Ciências Sociais, no 43, 1996.

, ARRETCHE, M. Condicionantes Locais da descentralização das políticas de saúde. Caderno CRH. Salvador. N. 39, p. 55-81. jul/dez.2003.

MERTINS, F.F.; MYSKIW, M.; SANFELICE, G.R. O Esporte e o Lazer na Estrutura Organizacional da Administração Pública Municipal. Licere, Belo Horizonte, v. 19, n. 3, p. 71-101, 2016.

MINHOTO, A. C. B. Federalismo, estado federalista e a revalorização do município: um novo caminho para o século XXI? Revista Brasileira de Políticas Públicas, Brasília, v. 3, n. 2, 2014.

NASCIMENTO, O.A.S.; LAZZAROTTI FILHO, A.; INÁCIO, H.L.D. As políticas públicas de lazer e esporte no município de Aruanã-GO. Pensar a Prática, Goiânia, v. 18, n. 4, out./dez. p. 864-879, 2015. 
SABATIER, P. Top-down and bottom-up approaches to implementation research: a critical analysis and suggested synthesis. Journal of Public Policy, Cambridge, 6, p. 21-48. 1986.

SANTOS, A. M. S. P. Federalismo no Brasil: uma abordagem da perspectiva dos municípios. Direito da Cidade, Rio de Janeiro, v. 3, n. 1, p. 95-124, 2011.

SANTOS, C. H.; GENTIL, D. L. A. CF/88 e as finanças públicas brasileiras. In: CARDOSO Jr., J. C. (Org.). A Constituição brasileira de 1988 revisitada: recuperação histórica e desafios atuais das políticas públicas nas áreas econômica e social. Brasília: Ipea, 2009, p. 123-160.

SANTOS, E.S.; CANAN, F.; STAREPRAVO, F.A. Investimentos na função desporto e lazer por parte dos municípios da Bahia de 2002 a 2011. Journal of Physical Education, Maringá, v. 29, n. 1, p. 2-10, 2018.

SANTOS, L. L. S. R. Gestão pública municipal de esporte no estado do Paraná: estrutura administrativa e financiamento. 118f. Dissertação (Mestrado em Educação Física) - Centro de Ciências da Saúde. Departamento de Educação Física. Universidade Estadual de Maringá, Maringá, 2016.

SANTOS, E. S.; STAREPRAVO, F. A. ; HIRATA, E. . Perfil das Prefeituras que descentralizaram o PELC de 2003 a 2012. Licere, v. 21, p. 71-88, 2018.

SILVA, T.D.; COUTO, A.M.S.; SANTOS, M.L.A. Análise da estrutura administrativa e financeira do esporte no município de Ipiaú-BA. Podium Sport, Leisure and Tourism Review, v. 3, n. 3, p. 77-87, 2014.

SOUZA, C. Federalismo e Descentralização na Constituição de 1988: Processo Decisório, Conflitos e Alianças. Dados, Rio de janeiro, v. 44, n. 3, p. 513-560, 2001.

SOUZA, C. Federalismo, desenho constitucional e instituições federativas no Brasil Pós-1998. Revista Sociologia e Política, Curitiba, v. 24, p. 105-121, jun. 2005.

TOMIO, F. R. de L. Comentários sobre a abordagem neoinstitucionalista. Revista Salamanca, Rioja, v. 1, p. 17-21, 2002.

VENTURIM, L. F; BORGES, C.N.; SILVA, D.S. Estratégias de gestão pública na prefeitura de Vitória/ES? O PELC e a intersetorialidade das ações. Licere, Belo Horizonte, v. 16, n. 4, p. p. 1-38. dez. 2013.

VERONEZ, Luis Fernando Camargo. O planejamento governamental e o orçamento do setor esportivo. In: CONGRESSO BRASILEIRO DE CIÊNCIAS DO ESPORTE, 15, 2007, Recife. Anais... Recife: CBCE, 2007.

\section{Endereço dos Autores:}

Edmilson Santos dos Santos

Rua Clóvis Beviláqua 160/02 
Salvador - BA - 41.603-120

Endereço Eletrônico: edmilson.santos@univasf.edu.br

Fernando Augusto Starepravo

Departamento de Educação Física

Avenida Colombo, n. 5.790

Bloco M-06 - Sala 002 Campus Universitário

Maringá - PR - 87020-900

Endereço Eletrônico: fernando.starepravo@hotmail.com 